Review

\title{
Passive Optical Access Networks: State of the Art and Future Evolution
}

\section{Tommaso Muciaccia, Fabio Gargano and Vittorio M. N. Passaro *}

Photonics Research Group, Department of Electrical and Information Engineering, Politecnico di Bari, via Edoardo Orabona n. 4, 70125 Bari, Italy; E-Mails: tommaso.muciaccia@ hotmail.it (T.M.); gargafa@gmail.com (F.G.)

* Author to whom correspondence should be addressed; E-Mail: vittorio.passaro@ poliba.it; Tel.: +39-080-59-638-50; Fax: +39-080-59-634-10.

Received: 5 September 2014; in revised form: 8 October 2014 / Accepted: 8 October 2014 / Published: 13 October 2014

\begin{abstract}
In the very last years, optical access networks are growing very rapidly, from both the network operators and the research interests points of view. Fiber To The Home (FTTH) is already a reality in plenty of real contexts and there has been a further stimulus to the proposal of new solutions and the investigation of new possibilities, in order to optimize network performance and reduce capital and operational expenditure. A complete and systematic overview of passive optical access networks is presented in this paper, concerning both the hot research topics and the main operative issues about the design guidelines and the deployment of Passive Optical Networks (PON) architectures, nowadays the most commonly implemented approach to realize optical fiber links in the access networks. A comparison of advantages and disadvantages of different multiplexing techniques is discussed, with specific reference to WDM-based networks, almost universally considered as the enabling technology for future proof bandwidth requirements. An exhaustive summary is also given about the-state-of-the-art of modulation and encoding techniques recently proposed by the scientific community, as well as the open challenges (such as colorless and coolerless ONUs) for telecom companies and international standardization compliance.
\end{abstract}


Keywords: access networks; PON; FTTH; NG-PON2; NG-PON3; WDM-PON; colorless ONU

\section{Standardization Evolution and Application Scenarios of Passive Optical Access Networks}

Nowadays, the deployment of optical access networks (OAN) represents one of the most important technological challenges for telecommunications operators. Huge investments have already been planned for partial or total replacement of traditional copper-based access networks, which remains a precious asset for incumbent operators but, at the same time, has become a bottleneck for the provisioning of ultra-broadband services to residential and business customers.

As a consequence, national and international strategies to deploy OANs have been designed, too. In 2009, the United States have activated the ambitious program "Connecting America: The National Broadband Plan" to provide $100 \mathrm{Mb} / \mathrm{s}$ downstream and $50 \mathrm{Mb} / \mathrm{s}$ upstream connections to one hundred millions American households and $1 \mathrm{~Gb} / \mathrm{s}$ connections to local communities by 2020 . In 2010, the European Union has set as one of the main targets in the "Digital Agenda" that, by 2020, 100\% of Europeans should have broadband access of above $30 \mathrm{Mb} / \mathrm{s}$ and $50 \%$ or more of European households should have access speeds above $100 \mathrm{Mb} / \mathrm{s}$ [1].

In the last few years, several approaches have been defined to deploy next generation access (NGA) networks. Various Fiber To The X (FTTX) solutions differ for the different fiber termination point in the optical distribution network (ODN), e.g., the local exchange in Fiber To The Cabinet (FTTC) solutions, or the boundary of living spaces in Fiber To The Home (FTTH) solutions [2].

Naturally, FTTH networks are by far the best performance ones, even if they are as well the most expensive ones to be rolled out. Although trenching constitutes the largest cost $(\sim 70 \%)$ to realize underground infrastructure [3], the remainder of costs $(\sim 30 \%)$ depends on chosen technological solutions: from this it follows the great importance of accurate techno-economic analysis to evaluate advantages and disadvantages of each implementation proposal, taking into account capital and operational expenditures. Detailed models have been proposed to analyze framework and scenarios, in order to describe the financial perspective and technical viability of a telecommunication investment project [4].

Moreover, besides technical options, other issues like regulatory and competitive aspects should be taken into account. Open access-based competition is generally required in modern scenarios: local loop unbundling is wholesaled by the network owner, typically through a regulated approach [5]. Infrastructure sharing can be developed at different levels, as conduit and collocation facilities, physical layer unbundling, through dark fiber leasing or optical layer unbundling, data link layer unbundling (bit stream services), e.g., through the implementation of virtual local area networks (VLAN), network layer unbundling, through policy-based routing to multiple internet service providers (ISP) [6].

Passive optical networks (PON) are actually considered the most cost-effective way to deploy FTTH networks. In fact, PONs are point-to-multipoint (P2MP) networks without any active equipment in the splitting remote node (RN). On the other hand, active optical networks (AON) are P2MP 
networks as well, but they require optical-electrical-optical conversion and Medium Access Control (MAC) switching in the RN. In literature, AONs are much less represented than PONs because of their limited use in real context and because they are less complex from the optical domain point of view, since they are based on single wavelength point-to-point links [7]. Another possibility to deploy FTTH OANs is the point-to-point P2P physical link from the central office (CO) to each user, but it is a more costly and less common solution, because no parts of physical infrastructure are shared. On the contrary, PONs and AONs reduce both roll-out per-user time and costs, especially in greenfield environments. Compared to AONs, PONs ensure higher reliability, simpler maintenance and reduced power consumption because of the absence of active elements in the ODN, so implying lower operational expenditure.

It is worth noting that reach-extended PONs (called long reach PON, LR-PON) have also been proposed recently. According to the preceding definition, these networks can still be considered "passive" since they use optical amplifiers and not reshaping, retiming and retransmitting (3R) regeneration, and therefore any conversion of the optical signal to the electrical domain is not needed. The presence of amplifiers in the ODN will require an additional power consumption and consequent operative cost, but it will enable higher power budget in order to extend the maximum available reach or the splitting ratio (and, therefore, the number of end users) of a single PON, allowing to consolidate the number of COs.

Since the greatest advantage of PONs is the infrastructure sharing, this means that signals for and from each user must be combined at the physical level through multiplexing techniques in downstream and multiple access techniques in upstream. Time division multiplexing (TDM) and time division multiple access (TDMA) are by far the most commonly adopted solutions assigning a time slot to each downstream and upstream channel. Up to now, TDM-PONs are the only PON model completely standardized by ITU-T, even if other possibilities have already been proposed, studied, optimized, tested and will be standardized in the very next years.

In the last fifteen years, the Full Services Access Network (FSAN) group has developed technical specifications that have been the basis for ITU-T standards. Broadband PON (BPON) has been the first complete standard defined by ITU-T in 2001 (reorganized in ITU-T G.983.1 $\div$ G.983.5 in 2005) which takes origin on ATM PON (APON) and provides $155.52 \div 1244.16 \mathrm{Mb} / \mathrm{s}$ downstream bitrate and $155.52 \div 622.08 \mathrm{Mb} / \mathrm{s}$ upstream bitrate, with $20 \mathrm{~km}$ available reach and up to 64 end-users [8].

In 2004, IEEE has introduced Ethernet-PON (EPON), an alternative standard (IEEE 802.3ah later included in the overall standard IEEE 802.3) using Ethernet as transport protocol instead of less performing ATM protocol and providing for symmetric $1.25 \mathrm{~Gb} / \mathrm{s}$ [9]. EPON has rapidly become the most common standard in Asia and, in 2009, has evolved in 10G-EPON (IEEE 802.3av) providing for $10 \mathrm{~Gb} / \mathrm{s}$ downstream and $1 \mathrm{~Gb} / \mathrm{s}$ upstream bitrate [10].

ITU-T response to EPON is the Gigabit-Capable PON (GPON). This standard (ITU-T G.984) has been introduced in 2004 and has encountered great success in Europe and America. It supports various bitrate options but it typically provides for $2488 \mathrm{Mb} / \mathrm{s}$ downstream bitrate and $1244 \mathrm{Mb} / \mathrm{s}$ upstream bitrate, with $30 \mathrm{~km}$ available reach and up to 128 end-users [11]. In 2010, XG-PON has been standardized (ITU-T G.987) as the GPON natural evolution, providing for $10 \mathrm{~Gb} / \mathrm{s}$ downstream bitrate and $2.5-10 \mathrm{~Gb} / \mathrm{s}$ upstream bitrate, with $20-60 \mathrm{~km}$ available reach and 64-128 end-users (longest available reach and highest number of end-users are conflicting requirements) [12]. 
PON international standards are summarized in Table 1.

Table 1. PON International Standards.

\begin{tabular}{ccccc}
\hline Technology & Standard & Year & Downstream Bitrate [Gb/s] & Upstream Bitrate [Gb/s] \\
\hline BPON & ITU-T G.983.1 $\div$ G.983.5 & 2001 & $\leqslant 1.25$ & $\leqslant 0.625$ \\
EPON & IEEE 802.3ah & 2004 & 1.25 & 1.25 \\
10G-EPON & IEEE 802.3av & 2009 & 10 & 1 \\
GPON & ITU-T G.984 & 2004 & 2.5 & 1.25 \\
XGPON & ITU-T G.987 & 2010 & $\leqslant 10$ & 10 \\
NG-PON2 & ITU-T G.989.1 (specifications) & 2013 & 40 & 10 \\
\hline
\end{tabular}

In the roadmap defined by the FSAN group, describing the evolution of OANs in the next years, $\mathrm{XG}-\mathrm{PON}$ has already been selected as the best candidate for NG-PON1 solutions, i.e., the next generation PONs. The following step will be represented by NG-PON2 solutions whose system requirements have already been standardized by ITU-T G.989.1 in 2013. NG-PON2 must support at least $40 \mathrm{~Gb} / \mathrm{s}$ aggregate downstream capacity and more than $10 \mathrm{~Gb} / \mathrm{s}$ in the upstream direction, with $40 \mathrm{~km}$ maximum passive fiber reach and up to $60 \mathrm{~km}$ by eventually using reach extenders, with more than 64 end-users connected by these networks. Moreover, NG-PON2 solutions should ensure compatibility with legacy systems GPON and XG-PON and with existing ODNs, saving long-lived infrastructure investments [13].

According to FSAN evolution path, which can be seen in Figure 1, coexistence with legacy solutions is absolutely advisable in brownfield contests where cost-effective deployment could be actuated through gradual migration to new standards [14]. On the other hand, in greenfield contests (e.g., rural areas) compatibility with legacy ODNs is not mandatory and therefore completely innovative solutions, overcoming traditional time division multiplexing, could be adopted. These new approaches could be eventually defined in future NG-PON3 standards.

Figure 1. FSAN evolution roadmap.

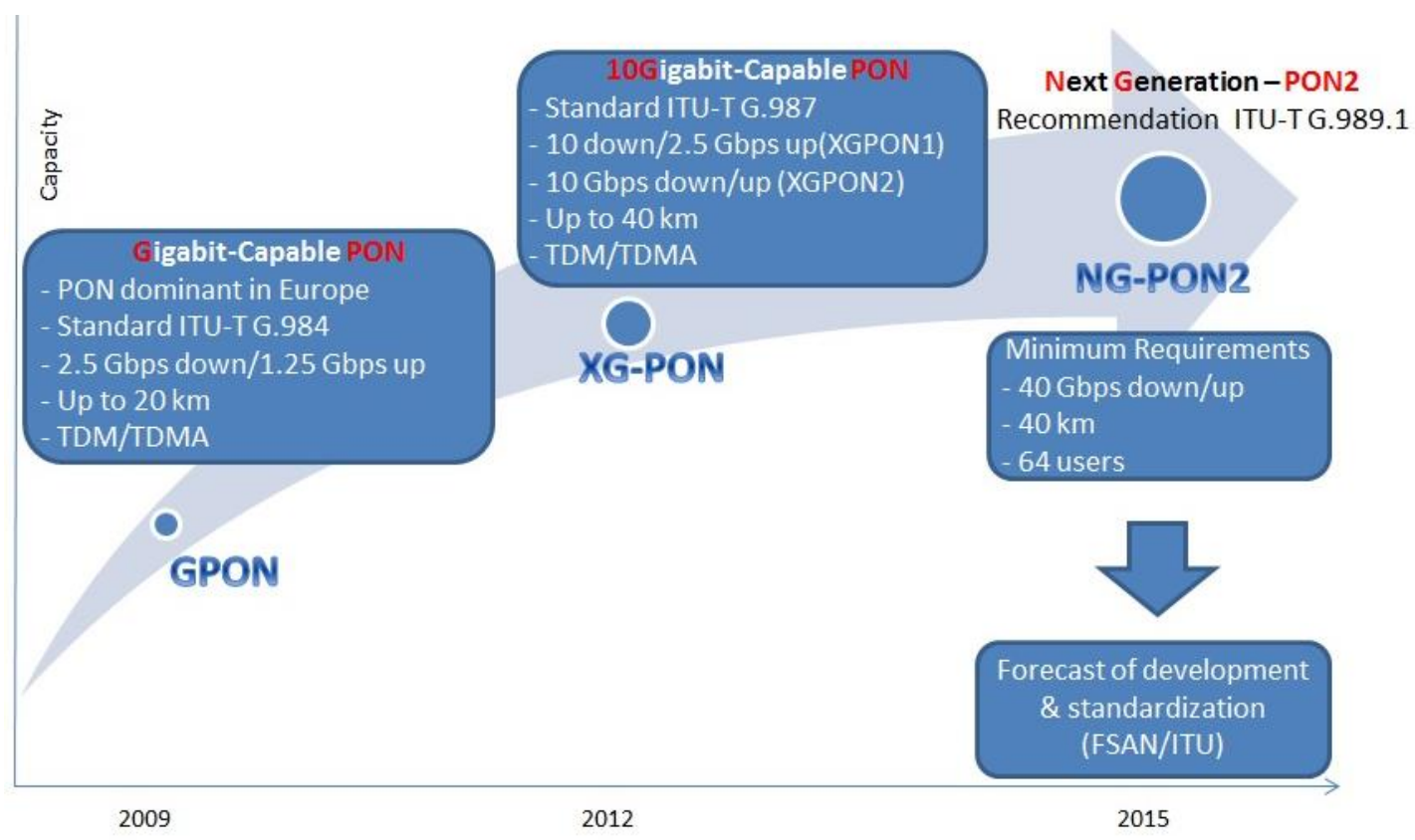




\section{PON Architecture and Design Guidelines}

In Figure 2 an extremely simplified PON architecture is depicted, which could be referred to any PON solution. According to terminology adopted since ITU-T G.983 standard, a generic PON tree is constituted by an optical line termination (OLT) placed in the $\mathrm{CO}$ and providing network-side interface of the OAN which, connected through ODN to $N$ optical network units (ONUs), provides the user-side interface. In the case of FTTH networks, each ONU is coincident with an optical network termination (ONT), because it includes the user port function. The ODN can include a certain number of splitting stages (typically one or two) placed in RNs (remote node). The components located in a RN have generally multiplexing and de-multiplexing functions, so they could be power splitters or more complex devices, but still rigorously "passive", with the meaning illustrated in the previous paragraph. RN could be the ideal place where an optical amplifier in LR-PONs can be installed. The RNs split the ODN in two or more fiber spans: feeder fiber is the one next to the CO; distribution fiber is the one exiting each port of the first splitting stage; drops are the optical link reaching each single users and is generally included in vertical cabling inside buildings.

Figure 2. Schematic representation of a PON.

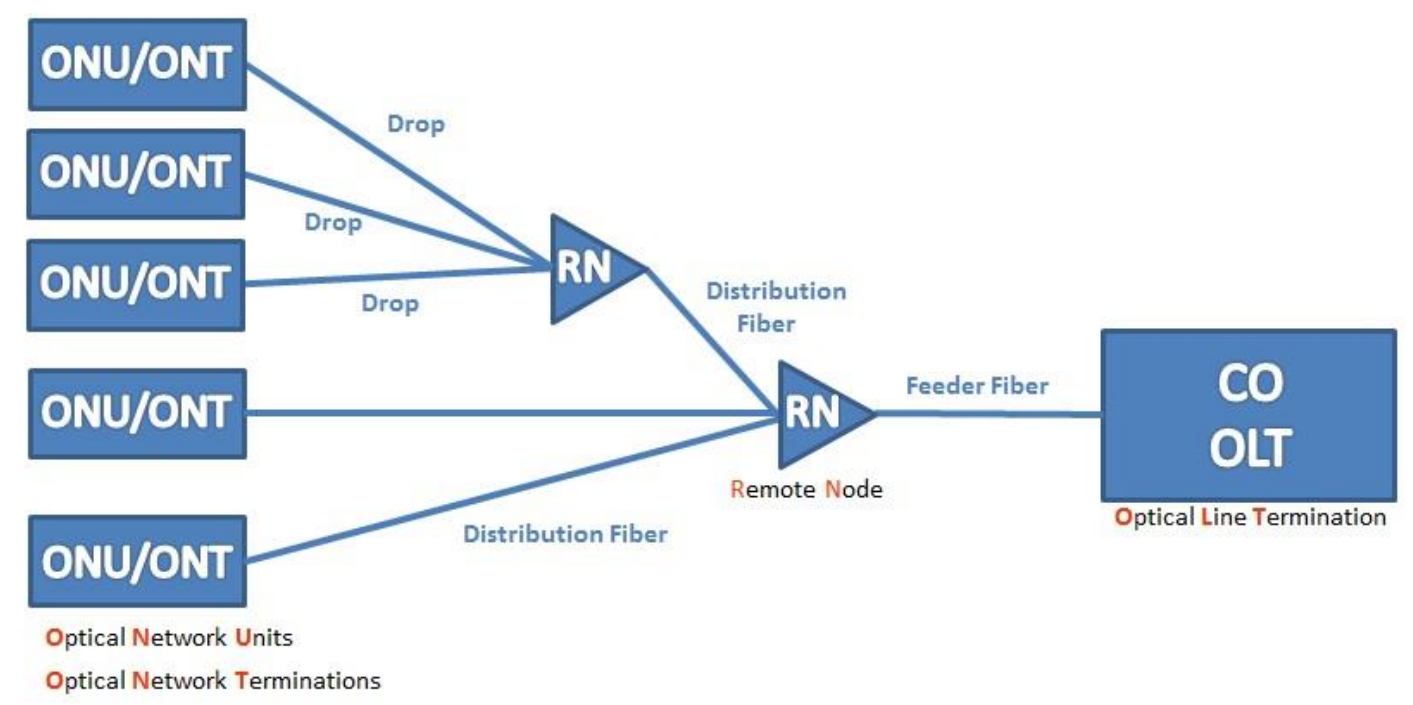

Both the ONUs and the OLT are equipped with optical transceivers providing for generation, modulation, detection and demodulation of optical signals.

Laser diodes are commonly used as optical sources; they are generally preferred to LEDs because they allow the emission of high powers (typically up to $100 \mathrm{~mW}$ ) and the possibility to be directly modulated at high frequencies (typically up to $25 \mathrm{GHz}$ ). In TDM-PONs, conventional Fabry-Pérot lasers are actually employed because they represent the cheapest solution. They are not suitable for WDM-PONs because of their multimodality due to great gain bandwidth. In these networks, distributed feedback (DFB) lasers could be preferred because of their good high-speed modulation properties due to their narrow bandwidth (less than a few megahertz). Unfortunately, they are still quite expensive and should require a thermoelectric cooler (TEC) module necessary to compensate the wavelength shift of about $0.1 \mathrm{~nm} /{ }^{\circ} \mathrm{C}$. VCSELs (vertical cavity surface emitting lasers) should be potentially more suitable for low-cost mass production, but this kind of sources emitting at $1550 \mathrm{~nm}$ 
are not still commercially available because their optical and thermal properties at this wavelength are not yet improved enough.

Although some semiconductor lasers could be modulated up to $40 \mathrm{~Gb} / \mathrm{s}$, systems operating at $10 \mathrm{~Gb} / \mathrm{s}$ or higher bitrates should use external modulation. In fact, chirping effect would become no more negligible and would cause spectral broadening. This aspect, combined with fiber group velocity dispersion (GVD), should limit the available reach. Both $\mathrm{LiNbO}_{3}$ Mach-Zehnder interferometers and electro-absorption modulators can be used in order to increase both bandwidth and extinction ratio and reduce the insertion losses. Their typical performances and basic properties are summarized in Table 2 [15].

Table 2. Modulators overview.

\begin{tabular}{lcc}
\hline & Mach-Zehnder Interferometer & Electro-Absorption Modulator \\
\hline Extinction Ratio & $20 \mathrm{~dB}$ & $20 \mathrm{~dB}$ \\
Modulation bandwidth & $100 \mathrm{GHz}$ & $50 \mathrm{GHz}$ \\
Modulation voltage & $<10 \mathrm{~V}$ & $<2 \mathrm{~V}$ \\
Insertion loss & Low & Moderate \\
Size & Large & Small \\
Monolithic integration & No & Yes \\
\hline
\end{tabular}

Optical receivers in PONs can employ PIN photodiodes or APDs (avalanche photodiodes). The latter can achieve a sensitivity of two orders magnitude higher than the former. In order to improve the overall receiver sensitivity, the bandwidth of the trans-impedance amplifier is commonly designed to be 0.7 times the bitrate, which is a reasonable trade-off between noise suppression by filtering and inter-symbol interference due to limited bandwidth. Some of the most meaningful parameters of PIN and APD are compared in the following Table $3[15,16]$.

Table 3. Photodetectors overview.

\begin{tabular}{lcc}
\hline & PIN & APD \\
\hline Responsivity & $1 \mathrm{~A} / \mathrm{W}$ & $100 \mathrm{~A} / \mathrm{W}$ \\
Bandwidth & $10 \mathrm{GHz}$ & $40 \mathrm{GHz}$ \\
Overall sensitivity & $-22 \mathrm{dBm}$ & $-30 \mathrm{dBm}$ \\
\hline
\end{tabular}

In the following Table 4, the most frequently employed optical fiber are compared about core diameter, cut-off wavelength (the lower limit for single mode operation), attenuation $\left(\alpha_{f i b e r}\right)$ and dispersion $(D)$ coefficients.

In TDM-PONs power splitters are placed in the RN, where a 1:2 splitter can be made with Y-branch or MMI (Multimode Interferometer) planar lightwave circuits or it could be realized by fusing two pieces of fiber with tapered core diameter to achieve weakly field confinement. A generic 1:N splitter can be obtained by cascading multiple 1:2 splitters. Power splitter/combiners strongly limits the power budget because of the high insertion losses $I L_{\text {splitter }}=\log _{2} N[\mathrm{~dB}]$.

In WDM-based PONs the RN is equipped with array waveguide gratings (AWG) providing for wavelength routing in the optical domain. Unlike power splitters, AWGs have fixed insertion loss (typically, from 2.5 to $6 \mathrm{~dB}$ ) regardless of the number of channels. Moreover, their spectrum periodicity allows their use in different optical wavelength ranges, e.g., the upstream and the 
downstream band, making it possible to be simultaneously used both as multiplexer and as demultiplexer. On the other hand, if full duplexing is realized at the same wavelength, the same AWG port cannot be assigned for both upstream and downstream, so a 2:N AWG must be used at the RN. An important issue for the use of AWG in PONs is a-thermal operation to ensure real-time wavelength consistency. It could be obtained by the usage of compensating negative thermo-optic coefficient or by mechanically movable plates.

Table 4. Optical fibers overview.

\begin{tabular}{lccccc}
\hline \multicolumn{1}{c}{ Denomination } & $\begin{array}{c}\text { ITU-T } \\
\text { Standard }\end{array}$ & Core Diameter $[\mu \mathrm{m}]$ & $\begin{array}{c}\text { Cut-Off } \\
\text { Wavelength }\end{array}$ & $\boldsymbol{\alpha}_{\text {fiber }}$ & $\boldsymbol{D}$ \\
\hline Graded-index multimode & G.651 & $50 \pm 3$ & - & $2 \div 4 \mathrm{~dB} / \mathrm{km}$ & - \\
Standard single mode & G.652 & $8.6 \div 9.5 @ 1300 \mathrm{~nm}$ & $1270 \mathrm{~nm}$ & $0.5 \div 1 \mathrm{~dB} / \mathrm{km}$ & $3.5 \div 20 \mathrm{ps} /(\mathrm{nm} \cdot \mathrm{km})$ \\
Dispersion-shifted single mode & G.653 & $7 \div 8.3 @ 1550 \mathrm{~nm}$ & $1270 \mathrm{~nm}$ & $<0.5 \mathrm{~dB} / \mathrm{km}$ & $<3.5 \mathrm{ps} /(\mathrm{nm} \cdot \mathrm{km})$ \\
Non-Zero-Dispersion single mode & G.655 & $9 \div 11 @ 1550 \mathrm{~nm}$ & $1480 \mathrm{~nm}$ & $<0.35 \mathrm{~dB} / \mathrm{km}$ & $<6 \mathrm{ps} /(\mathrm{nm} \cdot \mathrm{km})$ \\
\hline
\end{tabular}

The RN is also the ideal place to locate an eventual optical amplifier. In LR-PONs, in-line amplifier configuration is preferable to booster solution basically for two reasons: a booster amplifier would require very high saturation power not easily achievable and the optical signal reaches the amplifier input port when it has already been attenuated through the feeder fiber, avoiding the non-linear effects induced by high powers.

Optical amplifiers suitable for LR-PONs are erbium-doped fiber amplifiers (EDFAs), semiconductor optical amplifiers (SOAs) and Raman amplifiers (RAs). EDFAs can only operate near $1.55 \mu \mathrm{m}$. In order to amplify signals in the fiber second window, particular fluoride fibers doped with praseodymium (ZBLAN fibers) could be theoretically used, but their cost is still a strong limitation. RAs seem to represent a better solution because of the great flexibility in choosing amplification wavelength range, even if large pump power is required to obtain large gain. Also travelling-wave SOAs offer high flexibility and can provide large gain bandwidth, although their technology has not yet reached sufficient maturity. Hybrid configurations have also been proposed, e.g., SOA-Raman hybrid amplifier (SRHA) has been presented to obtain larger bandwidth by exploiting complementary spectra of both amplifiers.

The use of optical amplifiers could allow relaxed conditions about power budget, which is a very important design parameter, since most PONs are power-limited systems. Given a specified amplifier gain $G_{A}$, overall channel losses $C_{L}$, and photo-receiver sensitivity $S_{R x}$ needed to ensure a predefined $\mathrm{BER}$, the required power budget is defined as follows:

$$
P_{\text {budget }}=P_{T x}-S_{R x}>C_{L}-G_{A}+M_{S}
$$

where $M_{S}$ is the system margin allocated to maintain performance during the entire system lifetime. $C_{L}$ must take into account fiber, splitter, slice and connector losses and insertion losses of all the devices placed in the ODN. 
Group velocity dispersion (GVD) can be evaluated through the dispersion length $L_{D}$, i.e., the distance over which a Gaussian pulse broadens by a factor of $\sqrt{2}$ due to GVD and in absence of any other effect:

$$
L_{D}=\frac{2 \pi c}{4 \lambda^{2} f_{\text {sym }}{ }^{2}|D|}
$$

where a net channel bandwidth $B=2 f_{\text {sym }}$ is considered, being $f_{\text {sym }}$ the symbol rate. Equation (2) clearly shows how high symbol rates increase sensitivity to dispersion. Links operating at higher line rates need dispersion compensation devices to compensate the chromatic dispersion of the optical path. Several types of dispersion accommodation technologies are used, including passive dispersion compensation, self-phase modulation, prechirp and dispersion supported transmission [17]. Adaptive chromatic dispersion compensators are described in the recommendation ITU-T G.667 [18].

Polarization mode dispersion (PMD) can be evaluated through the PMD length, i.e., the distance over which the polarization mode dispersion effects are no more negligible:

$$
L_{P M D}=\frac{1}{4 P M D^{2} \cdot f_{\text {sym }}{ }^{2}}
$$

Long links operating at high symbol rate can require the use of polarization mode dispersion compensators (PMDCs) whose features are described in the recommendation ITU-T G.666 [19]. Both line PMDCs, in the middle of the transmission link, and PMDC receivers, with compensating functionalities integrated in the terminal, can be used [17].

Chirping-inducing self-phase modulation (SPM) can be neglected if the following condition is satisfied:

$$
P_{T x}<\frac{\alpha_{\text {fiber }}}{\gamma_{N L}}
$$

where $\alpha_{\text {fiber }}$ is the fiber attenuation coefficient and the non-linearity parameter is defined as:

$$
\gamma_{N L}=\frac{2 \pi}{\lambda} \frac{n_{2}}{A_{e f f}}
$$

being $A_{\text {eff }}$ the optical fiber modal area, $n_{2}$ the second order nonlinear core fiber refractive index and $\lambda$ the operative wavelength. Cross-phase modulation (XPM) can generally be considered negligible when the channel spacing is quite large (such as in CWDM wavelength grid), while four-wave mixing (FWM) can be ignored if the dispersion parameter is nonzero. Non-linear effects can be mitigated by using large effective area fibers (LEAFs), for example holey fibers. A micro-structured fiber, reported in 2004, shows an effective area of $130 \mu \mathrm{m}^{2}$, despite a quite large dispersion, $27 \mathrm{ps} /(\mathrm{nm} \cdot \mathrm{km})$ and a loss of $0.48 \mathrm{~dB} / \mathrm{km}[20]$.

\section{Operative Issues}

In this paragraph some operative issues will be briefly described: power consumption, security, monitoring and resiliency. Operative problems related to power consumption are strictly dependent on the exponential growth of services and user bandwidth requirements. Nowadays, about $10 \%$ of global $\mathrm{CO}_{2}$ emission is due to ICT systems and activities, but this value is expected to increase in the next 
few years. The contribution of access networks to overall consumption of wireline telecommunication systems is about $70 \%$, so it is much higher than in backbone and metropolitan networks, due mostly to the high number of user units [21]. For this reason, stand-by modality and dynamic techniques have been proposed and implemented to optimize the use of energy. Of course, OLT in the CO also gives an important contribution to power consumptions. In order to give a benchmark, the maximum power consumption of an OLT supplying 256 users in a commercial TDM-PON has been evaluated to be $200 \mathrm{~W}$, implying that the power consumption per user is about $0.8 \mathrm{~W}$ [22].

Nowadays, costs associated to energetic provisioning represent a high component of operative expenditure and the respect of recent strict standards is another contribution to overall outflow. In 2007, European Council has set a new target by 2020 to reduce gas carbon emission by $20 \%$ compared to emission levels in 1990 [23]. Moreover, gas carbon emission associated with OANs is related not only to network systems operations but also to their fabrication, transport, distribution and removal. Although the contribution of systems operation is strongly predominant, deployment-related energy consumption should not be ignored especially in FTTH PONs where a single fiber drop per user is needed. In a 15-years lifetime, neglecting all ONU contributions, $80 \%$ of overall energy consumption is related to production, transport and distribution of network assets, whose $83 \%$ is represented by passive ones [24].

Another diriment operative issue is related to the security in OANs. In most PON architectures, broadcast nature of downstream traffic makes information potentially accessible to all users on the PON tree. Actually, two typologies of security methods are adopted, the former is based on an authentication request sent from the OLT to the ONU through a password inside the data stream, the latter consists of encryption of downstream traffic.

TDM-PONs employ Advanced Encryption Standard (AES), therefore only the frame payload is encrypted and keys distribution is repeated several times during the connection. In spite of security countermeasures, networks are still vulnerable to some attack typologies, such as the presence of a false OLT, man-in-the-middle and denial-of-service attack [25]. Researchers will have to work on these challenges over the next few years.

Network monitoring and troubleshooting is a further important issue during the lifetime of the systems, from the installation testing to maintenance operations. Optical time domain reflectometry (OTDR) is a pulse-echo technique, based on Rayleigh back-scattering, used for decades to measure optical length and attenuation coefficient, localize and characterize splices, connectors, splitters, bend losses, faults, breakdowns and any kind of discontinuity along the optical link.

The presence of splitters in PONs makes critical the use of conventional OTDR techniques, because it determines a strong localized attenuation of back-scattering signal to be detected and monitored. In addition to this, discontinuities existing on single PON drops can produce reflective and non-reflective events overlapped with the ones associated to each other PON drop, and they can even overlap to ghost events, due to multiple reflections.

In order to overcome the P2MP problem, bidirectional measures can be performed or partial PON analysis can be carried on [26], making individual measure for each single branch [27].

Anyway, these open issues can be partially solved, in a more efficient way, by several expedients and innovative techniques such as the use of reference reflectors, innovative elaboration algorithms [28], multi-wavelength approach, polarization modulator [27], Brillouin frequency shift assignment (BFSA) 
to each drop, optical coding (OC) assignment to each ONU/ONT through passive optical out-of-band encoder. BFSA and OC techniques are actually important research topics [29]. Moreover, tunable OTDR [27] and similar techniques based on comparison between a reference amplified spontaneous emission signal and its reflection from an optical reflector have been proposed for WDM-PONs [30].

Network monitoring is strictly related to reliability and resiliency issues. Typical failures in PONs could be due to fiber link interruptions (e.g., cable cuts), performance degradation of splitter and AWGs or malfunctions of OLT and ONUs transceivers associated with aging or environmental factors.

The intensive deployment of FTTH PONs will lead to an increased concentration of customers, which will have an impact on network reliability and service availability. Moreover, if LR-PONs will increase the service area and allow the consolidation of the number of COs, on the other hand it will increase the number of customer potentially affected by a network failure [31].

Network downtime can be evaluated by multiplying mean time to repair (MTTR) and failures in time (FIT). Typically a network downtime is of the order of several tens of minutes per year [15].

Although the occurrence of failures is generally out of control of the physical network owner, their effects on the delivered services are dependent on the efficacy and efficiency of monitoring techniques and on the network topologies adopted by the provider. Protection switching is the solution to provide high reliability. It is based on the use of redundancies in network topologies to allow traffic rerouting around the deteriorated element. Automatic protection switching (APS) techniques and protocols can be introduced, in place of forced protection switching, in order to enable automatic restoration and reduce MTTR abruptly. Self-healing OANs (SHOANs) include automatic detection of failures (such as loss of signal, loss of frame, signal degrade) and APS triggered by the fault detection.

Optical switches could be adopted to enable commutation from the working path to the protection path in case of failure: either unidirectional or bidirectional schemes can be adopted. Although PONs are P2MP networks, their single spans (e.g., feeder fiber or single drops) can be considered P2P links where essentially two basic redundancy principles can be adopted: $1+1$ and 1:1 protection schemes. In a $1+1$ scheme, when the fault is detected, the traffic is switched from the working fiber to the protection fiber and working fiber becomes active again when the fault is cleared. In a 1:1 scheme, on the other hand, even when the fault is cleared, traffic is still directed through the protection fiber, which actually becomes the working link.

More complex N:M protection techniques have been recently proposed for PONs to enable flexible design of cost and reliability and the elimination of substantially unused backup equipment. These new solutions employ 2D and 3D MEMS switch [32]. In 2011, a SHOAN has been proposed in which two or more optical access architectures are partners of each other, and they are interconnected by elementary optical crossbar switches [33].

If fibers have to be duplicated, the ring topology have to be preferred to the most common tree topology because it allows a diversification of optical and/or physical path.

Current standards relate to unprotected tree topology, but sometimes they suggest several protection switching solutions. For example, BPON and GPON standards specify four reference models for resiliency and redundancy: type $\mathrm{A}$, where only the optical fibers are duplicated; type $\mathrm{B}$, where the OLT and the feeder fiber are duplicated (splitter at the RN has two ports on the OLT side); type C, where also the drops are duplicated in order to enable recovery from failures also on the ONU side; type D, 
where a combination of type $\mathrm{B}$ and $\mathrm{C}$ schemes, allowing the mixing of duplicated and non-duplicated ONUs. GPON should support $50 \mathrm{~ms}$ protection times [11].

IEEE standards does not suggest any protection model, but several protection schemes have been proposed in literature in the last years, also avoiding redundancy of equipment [34].

\section{Multiplexing Techniques}

TDM-PONs and WDM-PONs have already been mentioned in this paper. In particular, TDM-PONs standards have been overviewed in the first paragraph. TDM and WDM are the most discussed examples of multiplexing techniques used in PONs. Then, the object of this paragraph is just the comparison of these and other multiplexing techniques which have a strong impact on the definition of the general architecture presented in Figure 2 and, thereby, on its development costs. Main advantages and disadvantages of each technique are summarized in Table 5.

In TDM-PONs a time slot is assigned to each user to transmit and receive data on a shared optical carrier, typically allocated in the third optical fiber window for downstream and in the second optical fiber window for upstream. Complex algorithms of ranging and dynamic bandwidth assignment are generally used to regulate TDMA and avoid packet collision [35]. TDM-PON solutions can count on mature technology and cheap components. Therefore, they are the simplest and fastest way to deploy PONs according to a short-term technical and economic analysis.

The main drawback for TDM-PONs is the hard-limited scalability because of the compelling trade-off between number of users and per-user bandwidth. An increase in the user bit rate is quite difficult to be achieved because each ONU receiver works at the system bit rate, which is much higher than the effective user bit rate. Even by using high speed digital signal processors (DSP) or field-programmable gate arrays (FPGA), a further increase in the bit rate to more than $10 \mathrm{Gbit} / \mathrm{s}$ (as provided by XG-PON) will inevitably collide with electronics limitations.

Table 5. Multiplexing techniques for PONs.

\begin{tabular}{cll}
\hline Technique & \multicolumn{1}{c}{ Main Advantages } & \multicolumn{1}{c}{ Main Drawbacks } \\
\hline \multirow{2}{*}{ TDM } & Mature technology & Limited scalability \\
& Cheap components & Power consumption in CO \\
& Minimum bandwidth guarantee & Network security \\
\multirow{2}{*}{ WDM } & Transparency to modulation formats and bitrate & Floor space availability in CO \\
& Simplified unbundling & Photonics technology not yet consolidated \\
& Scalability & Multi-access interference \\
\hline \multirow{2}{*}{ OCDM } & Soft-limited technique & Mime synchronization not required \\
& Intrinsic data confidentiality & Multiplexing techniques not yet consolidated \\
\hline \multirow{2}{*}{ OFDM } & High spectral efficiency & Complex receivers \\
& Scalability & Multiplexing techniques not yet consolidated \\
\hline \multirow{2}{*}{ PDM } & Information capacity increasing & Complex receivers \\
\hline \multirow{2}{*}{ SDM } & Information capacity increasing & $\begin{array}{l}\text { Expensive deployment } \\
\text { Standardization needed }\end{array}$ \\
\hline \multirow{2}{*}{ TWDM } & Gradual migration from commercial solutions & $\begin{array}{l}\text { Limited scalability } \\
\text { Energy inefficiency }\end{array}$ \\
\hline
\end{tabular}


Up to now, bandwidth sharing is not perceived by users as a bottleneck but, in the next few years, new services will challenge the statistical multiplexing. Conventional burst-experience services, such as browsing, mailing and file-sharing, will step down in favor of video and multimedia services, generating a deeply different traffic typology based on continuous stream. Another scaling possibility is reducing the number of users on a single PON tree, thereby lowering the splitting ratio, but it would require more fiber to be rolled-out and so it would not be properly a cost-effective solution. Another drawback for TDM-PONs is represented by the power dividing splitters that decrease the optical power in ODN, so constituting energy inefficiency.

On the other hand, the introduction of wavelength division multiplexing (WDM) in PONs is not only driven by increasing the bandwidth requirements but it would lead to considerable improvements for future generation PONs. A WDM-PON provides P2P logical link to each user by assigning one or two operative wavelengths to each user. This network typology allows symmetrical services with reserved bandwidth, minimum bandwidth guarantee, simplified techniques to provide network security and transparency to modulation formats and bitrate [36].

In modern competitive scenarios, where passive infrastructures can be shared among several operators, WDM would provide simplified unbundling for regulatory compliance to ensure equivalence of input (EOI). Since optical interfaces can be kept physically separated, a channel set can be assigned to each operator to realize its own optical links.

WDM technology has been deployed for decades by telecom operators for backbone and transport networks: coarse WDM (CWDM) and dense WDM (DWDM) and their wavelength plan are respectively defined by ITU-T G.694.2 [37] and ITU-T G.694.1 [38]. Further channel bandwidth reduction can be performed to increase the number of users on the PON tree. Ultra-dense WDM (UDWDM) solutions have already been proposed and ensure network scalability for long-term evolution. WDM-PONs could favor the all-optical merger of OANs with metro networks by using ring architectures and reconfigurable optical add-drop multiplexers (ROADMs) for wavelength routing, such an architecture allowing high scalability for the entire system and active traffic adaptation [39].

In addition to this, WDM-PONs can provide flexible and various services. A new architecture has been recently proposed to support wireless access traffic, optical virtual passive network (VPN) communications and conventional wired services [40].

Of course, WDM-PONs will require more complex devices compared to conventional TDM-PONs, therefore technological maturity of high-performance photonic devices will be required. To this aim, the evolution of silicon photonics will be crucial to obtain high reliability and low cost for large-scale application. The essential components required will be a-thermal AWGs, WDM transmitter arrays at the OLT, narrow-band optical filters and colorless and coolerless ONUs.

One of the main drawbacks for WDM-PONs is the need for a higher number of transceivers at the OLT compared to TDM-PONs. This implies larger floor space availability in the CO and higher power consumption in the CO. Anyway, in order to evaluate a fair comparison between WDM- and TDM-PONs, it is worth noting that WDM-PONs would be by far more energetically efficient if equal user bitrate is considered, because ODN losses are reduced by the replacement of power splitters with AWGs in the RNs.

PONs based on optical code division multiplexing (OCDM) represent a possible alternative to WDM-PONs for future-proof band consuming services. OCDM is a soft-limited multiplexing technique. 
Once given the overall optical bandwidth and user bitrate, the number of users is not strictly imposed but it depends on the orthogonality of codes assigned to each channel. M-sequence codes, Kasami codes, Gold codes and Hadamard codes have been proposed in literature, because they exhibit good auto-correlation and cross-correlation properties. Since different channels can only be quasi-orthogonal, multi-access interference (MAI) must be taken into account, through signal-to-noise ratio (SNR) degradation:

$$
S N R=\frac{S}{(K-1) S+\sigma^{2}}=\frac{1}{(K-1)+\frac{\sigma^{2}}{S}}
$$

where $K$ is the number of contemporary users transmitting on the same OCDM-PON tree and $S$ and $\sigma^{2}$ are respectively their signal and noise average power [41].

Different implementations of OCDM-PONs have been proposed, mostly gatherable into two main categories: spectrum-sliced and time-sliced techniques. Spectrum-sliced solutions are based on the assignment of a spectral signature to each data-flow, where the signature is obtained through a combination of spectral slices originated by filtering a broadband light source (BLS) through narrow-band optical filters (e.g., fiber Bragg gratings). For this reason, these solutions are also denominated in literature as spectral amplitude coding OCDM (SAC-OCDM). A SAC-OCDM PON has been proposed in 2012, employing dynamic cyclic shift (DCS) codes and AND subtraction technique to suppress the effect of MAI [42]. However, spectrum-sliced solutions have some drawbacks, as the use of BLSs limits the modulation speed and, since optical bandwidth is quite large, dispersion issues become relevant. In time-sliced techniques a signature sequence is impressed on signals in the time domain. This could happen in the electrical or in the optical domain. In the first case, the multiplexing technique is often referred as CDM over fiber (COF), but in this paper it has been classified under OCDM since it is based on the same working principle, although by applying a different implementation. As the second possibility, super-structured fiber Bragg gratings (SS-FBG) have been proposed. A SS-FBG (see Figure 3) is a standard FBG with rapidly varying spatial refractive index of uniform amplitude and pitch on which a slow spatial refractive index modulation is superimposed [41]. By connecting a pulsed optical source, an optical circulator and a SS-FBG time-sliced phase encoder/decoder can be implemented, and a convolution between the input impulse and the SS-FBG impulse response (i.e., the signature) can be obtained.

The greatest advantage obtained by such a configuration is that neither time synchronization nor precise optical timing is required. Moreover, intrinsic data confidentiality is achieved, since each user multiplies and de-multiplies the data-stream with a different code.

Coexistence of TDM and OCDM in the electrical domain on the same ODN has been demonstrated in 2009 [48]. This solution is particularly interesting because it allows coexistence with GPON legacy systems and combination of best-effort and guaranteed-bandwidth services [43].

PONs based on orthogonal frequency division multiplexing (OFDM) are up to now theoretically the most performing networks, since they can provide up to $100 \mathrm{~Gb} / \mathrm{s}$ per user and easy scalability. In OFDM-PONs orthogonal sub-bands are modulated through advanced modulation techniques. High channel spectral efficiency can be obtained through sub-band overlapping. On the other hand, OFDM-PONs would require very complex receivers based on high-speed DSPs and FPGAs. 
Figure 3. Working principle of an SS-FBG.

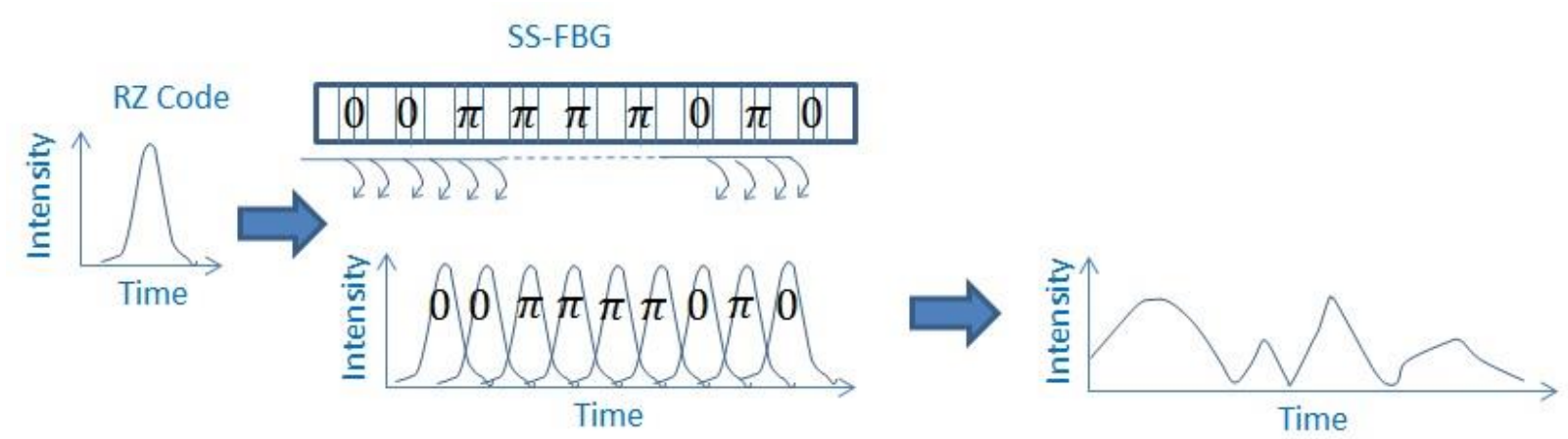

PONs based on polarization division multiplexing (PDM) and space division multiplexing (SDM) represent more unconventional solutions, actually far from commercial development. PDM-PONs are based on the exploitation of both orthogonal polarizations at the same wavelength. Although it would increase the information capacity of the fiber, since polarization state rotates along fiber propagation, it would be quite difficult to distinguish the two contributions at the receivers.

SDM-PONs can be implemented in several ways, i.e., through multiple bonded fibers (but it would be trivial and expensive), through multi-core fibers (MCF) or mode division multiplexing (MDM) in multimodal fibers [44]. PONs using MCFs and MDMs have not yet been studied in deep by university and industry researchers, probably because they are not seen as an attractive opportunity by operators. Moreover, they would need standardization to be implemented in a competitive context.

Beyond the aforementioned multiplexing techniques, it is worth noting that hybrid configurations exploiting the advantages of different technologies have not only been proposed in literature, but they probably represent the best way to upgrade the actual network capacity.

TWDM-PON architecture is a hybrid TDM-WDM solution, which has received great interest by the scientific community and international organizations for standardization. In ITU-T G.989.1, TWDM-PON has already been recommended as one of the possible technological solutions especially, for gradual migration scenarios to allow the reuse of existing ODNs [11]. In a TWDM-PON several TDM systems (e.g., GPON or XGPON) are stacked through CWDM or DWDM, then scheduling algorithms will be needed to reconfigure wavelengths and time slots dynamically, which will be the evolution of actual DBAs [44].

A hybrid DWDM-TDM LR-PON has been presented in 2011 with record performance in terms of reach $(135.1 \mathrm{~km})$, number of users (8192 ONUs) and aggregate capacity (symmetric $320 \mathrm{~Gb} / \mathrm{s}$ ), using in the architecture an EDFA to provide the gain to overcome the large fiber and splitting losses [45].

TWDM-PON certainly represents the more cost-effective architecture for very next years, but they cannot give a long-term solution for the same reason explained about TDM-PON disadvantages. They will be probably replaced by pure WDM-PONs, when WDM technology will become more mature and cheap.

WDM-OCDM architectures have been also proposed, but they still are in an embryonic stage, with a transmission capacity of $1.24 \mathrm{THz}$ reached in 2010, and spectral efficiency of $0.41 \mathrm{bit} / \mathrm{s} / \mathrm{Hz}$ [46].

In 2012, $1.2 \mathrm{~Tb} / \mathrm{s}$ symmetric WDM-OFDM-PON has been demonstrated. Over $90 \mathrm{~km}$ have been reached with 1:32 passive split and 10/1.25 Gb/s guaranteed peak rate in downstream and upstream 
direction, respectively [47]. Also energy-efficient WDM-OFDM-PONs have been experimentally demonstrated in 2012. The architecture proposed uses an opto-mechanic switch at the OLT to share the OFDM module among several users as a solution for a context with low traffic demand (e.g., non-peak hours of the day) [48].

Other configurations will probably be proposed in the next years for new generation PONs. Certainly new proposals will be evaluated on the base of power consumption, co-existence with legacy systems, spectral flexibility and resilience of the network. In Figure 4 the probable evolutionary scenario for PONs is sketched. In the next years several TDM systems, such as GPON and XG-PON, will be stacked through CWDM multiplexing, therefore TWDM PONs will replace conventional TDM-PONs especially in denser metropolitan areas. OCDM- and OFDM-PONs can be expected to be developed in specific contexts where standard compliance is not requested, e.g., for trial deployments or scientific laboratories.

Figure 4. PON evolutionary scenario.

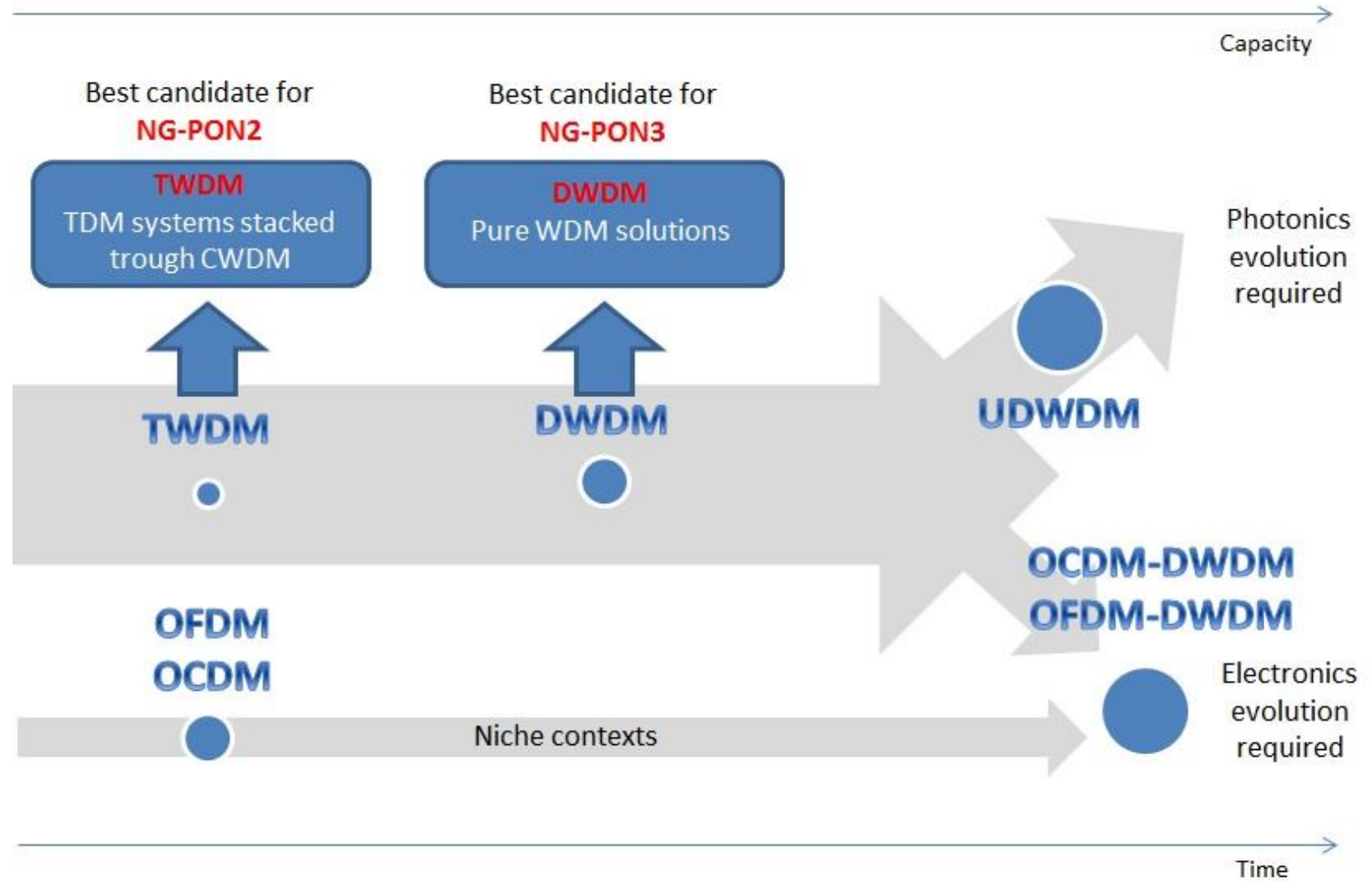

DWDM can be expected to be the main long-term solution for multiplexing in future PONs and, therefore, DWDM-PONs can be considered the strongest candidates for future NG-PON3 standards.

In order to further increase the number of users on a single PON tree, two future trends can be predicted: a progressive channel bandwidth shrinking in favor of UDWDM solutions or the adoption of innovative multiplexing techniques (e.g., OCDM and OFDM) over DWDM wavelength grid. The first possibility will be mainly bound by the technological improvements of photonic devices (e.g., sources, filters, AWG, etc.), the second possibility will essentially depend on electronics evolution in order to develop low-cost and high-speed DSPs and FPGAs. 


\section{Modulation and Encoding Techniques}

Once defined the multiplexing techniques to be employed in the PON, appropriate modulation and encoding solutions must be chosen for the various multiplied channels. In the last few years, increasing research efforts have been involved in finding modulation with higher performances while trying to keep simple the required components and overall architecture.

The technique conventionally adopted is the intensity modulation with direct detection (IM-DD), which is based on on-off keying (OOK). Up to now, it is used in every commercial TDM-PON standard. In fact, this solution is by far the simpler and more cost effective but, on the other hand, it has low spectral efficiency and scalability. Then, transceivers become expensive if high bitrate is required and physical damages appear. If direct modulation schemes are employed, chirping effect, due to temporary carrier density change in the laser active region, produces undesired phase changes and consequent frequency modulation and GVD, if Equation (4) is no longer satisfied.

The emerging of DWDM- and UDWDM-PONs will require an increasing spectral efficiency due to channel-limited bandwidth. Therefore, advanced multilevel modulations have been proposed to increase the bitrate while keeping low the signal bandwidth. If an alphabet having $\mathrm{M}$ symbols is used, the relationship between symbol rate $f_{\text {sym }}$ and bit rate $f_{b}$ is ruled by the well-known equation:

$$
f_{\text {sym }}=\frac{f_{b}[\text { bit } / \mathrm{s}]}{\log _{2} M}[\mathrm{sym} / \mathrm{s}]
$$

Innovative modulations will require an improvement in optical equipment to be employed in future PONs. Especially high linearity and dynamic range will be needed for optical receivers.

M-ary amplitude shift keying (M-ASK), M-ary phase shift keying (M-PSK) and M-ary amplitude phase shift keying (M-APSK) have been proposed. Some constellation diagrams are depicted in Figure 5. In particular M-APSK can obtain an optimal distribution of symbols in the complex plane in terms of transmitted power minimizing. Rectangular constellation diagrams (i.e., quadrature amplitude modulation, QAM) or concentric ring constellation diagrams can be implemented. The k-th symbol in M-APSK constellation is described as follows:

$$
s_{k}=A_{k} e^{j \vartheta_{k}}
$$

If $A_{k}$ is constant an M-PSK constellation diagram is obtained with constant envelop and theoretical insensitivity to attenuation, if $\vartheta_{k}$ is invariant an M-ASK (also called pulse amplitude modulation, PAM) constellation diagram is obtained which would need a simple envelope detector. M-PSK and M-APSK can require two typologies of optical receivers, i.e., coherent receivers (homodyne or heterodyne) which need local oscillator synchronized with the transmitted optical carrier, $90^{\circ}$ degrees optical hybrid, photodiodes, trans-impedance amplifiers (TIA) and DSP, and incoherent receivers, which need only $90^{\circ}$ degrees optical hybrid for phase detection, an additional photodiode for amplitude level detection, TIAs and DSP.

Coherent receivers can obtain better performance (about $3 \mathrm{~dB}$ SNR) and are suitable for long haul transmissions, even if they have been proposed for WDM-PONs, too [49]. In general, incoherent receivers are naturally less expensive and more suitable for PONs and OANs. On the other hand, incoherent solutions need the pilot carrier transmission on the orthogonal mode compared to signal 
propagation mode or the use of differential encoding (in this last case, self-coherent detection is implemented).

Figure 5. Advanced modulation constellation diagrams.

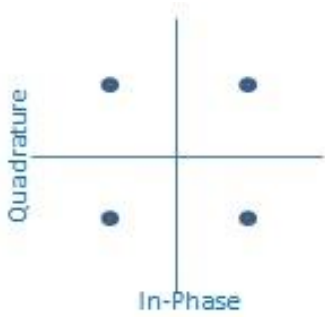

QPSK

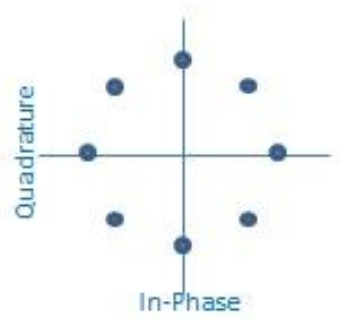

8PSK

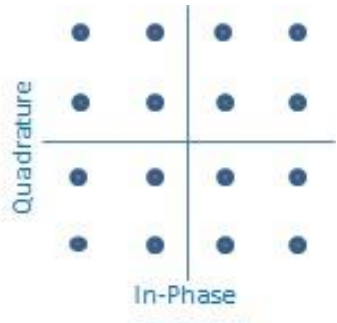

160AM

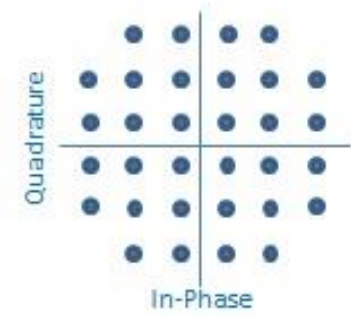

320AM

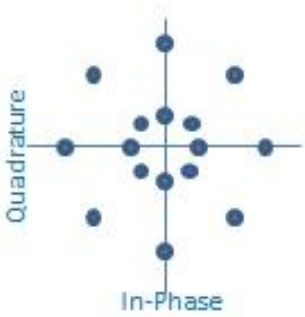

2ASK-8PSK

The use of differential encoding could be useful also for the use of the same wavelength for both downstream and upstream transmission, which is an option to enhance the bandwidth usage. Differential-PSK (DPSK) constant envelop, for example, makes it easy to re-modulate at the ONU the downstream signal into the OOK upstream signal. Even if some problems related to Rayleigh backscattering arise, symmetrical operation at $10 \mathrm{~Gb} / \mathrm{s}$ over $25 \mathrm{~km}$ reach has been experimentally demonstrated [50]. A symmetric $10 \mathrm{~Gb} / \mathrm{s}$ WDM-PON has been recently proved to reach $80 \mathrm{~km}$ distances without using any remote amplification, by 4-PSK (QPSK) in the upstream direction [51].

An optimized differential-QPSK (DQPSK) receiver in silicon with germanium photodiodes and a $2 \times 4 \mathrm{MMI} 90^{\circ}$ hybrid has been presented and tested for $10 \mathrm{~Gb} / \mathrm{s}$ and $20 \mathrm{~Gb} / \mathrm{s}$ [52].

Receiver complexity is enhanced by the necessity of a clock recovery system for signal demodulation. Methods proposed up to now for this purpose can be classified into two categories, electro-optical methods, which exploit FWM, EAMs or non-linear optical mirror (NOLM), and all-optical methods, which are the best performing ones and allow demodulation speed of the order of several $\mathrm{Gb} / \mathrm{s}$.

In order to optimize the bandwidth allocation, single sideband modulation (SSB) is used since both upper and lower sideband share the same informative content. In this way, spectral efficiency is doubled, but complex filters with theoretical null transition band are required.

Frequency shift keying (FSK) and polarization shift keying (PolSK) have been also recently proposed. In particular, a WDM-OFDM-PON architecture has been demonstrated in 2010, which uses a multicast $2.5 \mathrm{~Gb} / \mathrm{s}$ PolSK signal in overlay on unicast signals [53].

Modulation techniques are strictly related to encoding techniques, which deal with the way data are formatted to make the systems more power efficient, spectrally efficient, noise or jitter immune, resilient to other undesired effects. 
Non-return to zero (NRZ) and return to zero (RZ) encoding are by far the most conventional solutions for IM-DD or M-ASK modulations, where RZ would be preferable for dispersion resilience. Since optical pulses have the same length independently from the transmitted bit, dispersion produces the same effects on each pulse so they can be analogically or digitally compensated. RZ drawback is a larger bandwidth required if compared to NRZ encoding.

Inverse RZ (IRZ) has been proposed for downstream data encoding because the power is transmitted both for mark and space symbol, so signal power is higher and better distributed in time domain to allow re-modulation on the same wavelength from the ONU with higher extinction ratio. At the receiver, an inverting TIA after the photodiode is sufficient to rebuild the RZ sequence. Modified duo-binary RZ (MDRZ) and carrier-suppressed RZ (CSRZ) have been also proposed to improve the receiver quality factor in high bit rate WDM-PONs [54].

Duo-binary IRZ has been demonstrated to be particularly dispersion-tolerant. In fact, this encoding technique has been proposed for $80 \mathrm{~km}$ reach WDM-PON with $10 \mathrm{~Gb} / \mathrm{s}$ downstream and $2.5 \mathrm{~Gb} / \mathrm{s}$ upstream [55]. Dicode and modified duo-binary encoding have been proposed in 2012 for mitigating both Rayleigh backscattering and chromatic dispersion [56].

\section{Main Technological Open Challenges}

One of the main obstacles to be removed for large-scale application of new generation PONs is the cost of ONUs, which will require complex optical and electronic systems. From the optical point of view, the main interesting challenge is related to the use of colorless ONUs for cost-effective solutions in WDM-PONs.

Colorless ONUs would provide for wavelength independent operation. Colored wavelength specific operation would be difficult to be managed for inventory issues, and wavelength selective operation would be expensive, considering the state-of-the-art of available technology.

In fact, tunable sources have been proposed. For example, a tuning mechanism for VCSELs uses a micro-electro-mechanical system (MEMS) structure that changes the cavity length through the electrostatic control with a few microsecond tuning speed and $20 \mathrm{~nm}$ tuning range. VCSELs could be a strong candidate for OANs but only if their fabrication techniques will mature.

Colorless ONUs should also be coolerless, that is they would not require thermo-electric cooler (TEC) modules in order to reduce the power consumption. In fact, necessity of TEC controllers to allow thermal stability is another drawback of tunable sources, whose emission wavelength is intrinsically sensitive to temperature variations.

Several approaches have been proposed to realize colorless and coolerless ONUs. The wavelength of these optical sources is not determined by the gain media but by external factors, such as optical filters or injected signals, in order to reduce the consequences of temperature changes or aging effects at the ONU.

The use of tunable filters to obtain colorless operation actually is not a hot research topic, because it would provide a simple solution but being bulky and expensive [31]. Nevertheless, some interesting proposals have been advanced in the last years in this field. A thermally tunable filter, fabricated with integrated micro-ring resonators with specific polymers (PMATRIFE/PVCi), has been proposed in 2012 , having a tested range of $120 \mu \mathrm{m}$ to $180 \mu \mathrm{m}$, free spectral range (FSR) from $2.0 \mu \mathrm{m}$ to $1.37 \mu \mathrm{m}$; 
extinction ratio around $10 \mathrm{~dB}$ to $20 \mathrm{~dB}$ for each of the two ports (drop and out), thermal coefficient measured as $-0.11 \mathrm{~nm} /{ }^{\circ} \mathrm{C}$, maximum time estimated to reach equilibrium temperature $40 \mathrm{~ms}$. Considering the modeled response time, the electrical consumption is assumed to be very low [57].

Spectrum-sliced BLS (SS-BLS) solution is obtained by slicing the spectrum of a BLS with a narrow-band optical filter in such a way that a unique wavelength for each channel is achieved. The optical filtering could be implemented by an AWG. This technique has several disadvantages since a narrow part of the spectrum is used and the signal power is degraded, thereby an optical booster should be used to restore the power budget. BLSs are quite inexpensive (a super-luminescent diode would be sufficient), but their spectrum limits the number of users and crosstalk limitation could also occur.

Solutions based on the use of injection-locked Fabry-Pérot (IL-FP) laser diodes have also been proposed. Since Fabry-Pérot laser cavities can have the property to be multimodal, if an external optical signal is injected into the cavity, only one mode can be excited. Therefore an external reference seed is sent from the $\mathrm{CO}$ to the ONU to synchronize the user transceiver on a well-defined wavelength. Also this technique is quite inexpensive but backscattering problems could require additional fibers to send the seed and the number of users would be limited by locking range.

Most of colorless ONUs solutions are based on the use of SOAs and reflective SOAs (RSOAs), whose use is considered strategic because they can modulate and amplify the signal simultaneously instead of using separate devices, which would lead to extra manufacturing cost. RSOA are preferable because the signal travels twice through the device allowing double gain. Conventional RSOA bandwidth in direct modulation is about $2 \mathrm{GHz}$ and it depends on the carrier lifetime. This feature makes RSOA employable in $1.25 \mathrm{~Gb} / \mathrm{s}$ and $2.5 \mathrm{~Gb} / \mathrm{s}$ systems keeping low the inter-symbolic interference, even if amplified stimulated emission (ASE) noise should be taken into account. Recent works have shown RSOA operation at $10 \mathrm{~Gb} / \mathrm{s}$ without electronic equalization. In fact, a RSOA with fiber-to-fiber $22.8 \mathrm{~dB}$ gain, $3 \mathrm{~dB}$ ASE and $30 \mathrm{~nm}$ bandwidth has been demonstrated [58]. RSOA-based systems performance is actually limited by RSOA limited saturation power and chirping effect which limits the power budget [59].

Two possibilities have been proposed to use RSOAs in ONUs. The former is to modulate through RSOA carrier transmitted from the $\mathrm{CO}$ (backscattering problems can require dual feeder fibers), the latter is to re-modulate through RSOA the downstream data from the CO (reduced extinction ratio can require dual feeder fibers, too). In the former the upstream wavelength grid is generated at the central office (this is called wavelength seeding), e.g., through a SS-BLS. In the latter, full-duplex communication is achieved [60]. Various techniques can be adopted, such as aforementioned encoding and modulation schemes [51], different modulations techniques at OLT and at ONU (e.g., ASK/FSK), or the same ASK modulation technique at OLT and at ONU but with different power offset levels.

Currently RSOAs are still expensive for large-scale applications in PONs and they require TEC modules, so they actually do not represent a coolerless solution. Anyway, some RSOA based on new materials have been proposed to avoid TECs, making them less expensive and power consuming. Other options, which have been considered for similar purposes, are based on the use of EAMs and reflective EAMs (REAM) [61]. 


\section{Conclusions}

PON deployment issues and future solutions have been widely overviewed, existing standards have been compared and FSAN roadmap has been illustrated. Terminology and architectural aspects have been presented. Several simple design guidelines have been given to take into account undesired effects, such as GVD, PMD and SPM. Power consumption, security and network monitoring and troubleshooting issues have been briefly described as the main operative issues in PONs. Actually adopted countermeasures and open challenges have been also presented.

Although WDM appears as the most future proof technology, a comparison of all PON multiplexing techniques, such as OCDM, OFDM, PDM, SDM, has been proposed, summarizing their main advantages and drawbacks. Some possible trends for future evolution of PONs have been forecasted on the base of the complexity required by innovative multiplexing techniques.

Modulation and encoding techniques for future PONs have been presented as well. Multilevel modulation schemes, such as M-APSK, have been found as necessary evolution to make WDM-PONs scalable by reducing the channel bandwidth. Moreover, IRZ and other advanced codes have been briefly overviewed to stress their importance to make networks more resilient to undesired effects. Finally, several solutions for colorless and coolerless ONUs have been reported, such as SS-BLS, IL-FP and RSOA-based techniques.

Some intriguing references to recent scientific proposals and results have been suggested to give some examples of the huge research efforts involved in the very last years to propose innovative PON solutions in order to fulfill the requirement of future bandwidth-hungry telecommunication services.

\section{Conflict of Interest}

The authors declare no conflict of interest.

\section{References}

1. Ciccarella, G.; Ghibaudo, C.L.; Guarino, F. NGAN nel mondo: Piani e sostenibilità economica. Notiziario Tecnico-Telecom Italia 2012, 11, 10-23.

2. Katsianis, D.; Rokkas, T.; Neokosmidis, I.; Tselekounis, M.; Varoutas, D.; Zacharopoulos, I.; Bartzoudi, A. Risks Associated with Next Generation Access Networks Investment Scenarios. IEEE Netw. 2012, 26, 11-17.

3. Casier, K.; Vanhaverbeke, J.; Lannoo, B.; van Ooteghem, J.; Verbrugge, S.; Meersman, R.; Colle, D.; Pickavet, M.; Demeester, P. Economics of FTTH: A comparative study between active and passive optical networks. In Proceedings of the 48th FITCE Congress, Prague, Czech Republic, 3-5 September 2009.

4. Kantor, M.; Wajda, K.; Lannoo, B.; Casier, K.; Verbrugge, S.; Pickavet, M.; Wosinska, L.; Chen, J.; Mitcsenkov, A. General Framework for Techno-Economic Analysis of Next Generation Access Networks. In Proceedings of the 12th International Conference on Transparent Optical Networks (ICTON), Munich, Germany, 27 June-1 July 2010. 
5. Banerjee, A.; Sirbu, M. Towards technologically and competitively neutral Fiber To The Home (FTTH) infrastructure. In Proceedings of the 31st Research Conference on Communication, Information and Internet Policy (TPRC), Arlington, Virginia, 19-21 September 2003.

6. Banerjee, A.; Sirbu, M. Fiber To The Premise (FTTP) industry structure: implications of a wholesale-retail split. In Proceedings of 2nd International Conference on the Broadband Networks, Boston, MA, USA, 7 October 2005.

7. Larsen, C.P.; Gavler, A.; Wang, K. Comparison of Active and Passive Optical Access Networks. In Proceedings of 9th Conference on Telecommunications Internet and Media Techno Economics (CTTE), Ghent, Belgium, 7-9 June 2010.

8. International Telecommunication Union. Broadband optical access systems based on Passive Optical Networks (PON); Recommendation ITU-T G.983.1, 2005.

9. IEEE. Local and metropolitan area networks-Part 3: CSMA/CD Access Method and Physical Layer Specifications Amendment: Media Access Control Parameters, Physical Layers, and Management Parameters for Subscriber Access Networks; Standard for Information Technology IEEE 802.3ah, 2004.

10. IEEE. Local and metropolitan area networks_Part 3: CSMA/CD Access Method and Physical Layer Specifications Amendment 1: Physical Layer Specifications and Management Parameters for $10 \mathrm{~Gb} / \mathrm{s}$ Passive Optical Networks; Standard for Information Technology IEEE 802.3av, 2009.

11. International Telecommunication Union. Gigabit-capable passive optical networks (GPON): General characteristics; Recommendation ITU-T G.984.1, 2008.

12. International Telecommunication Union. 10-Gigabit-capable passive optical network (XG-PON) systems: Definitions, abbreviations and acronyms; Recommendation ITU-T G.987, 2012.

13. International Telecommunication Union. 40-Gigabit-capable passive optical networks (NG-PON2): General requirements; Recommendation ITU-T G.989.1, 2013.

14. Chanclou, P.; Cui, A.; Geilhardt, F.; Nakamura, H.; Nesset, D. Network Operator Requirements for the Next Generation of Optical Access Networks. IEEE Netw. 2012, 26, 8-14.

15. Kazovsky, L.G.; Cheng, N.; Shaw, W.; Gutierrez, D.; Wong, S. Broadband Optical Access Networks; John Wiley \& Sons: Hoboken, NJ, USA, 2011.

16. Kharraz, O.; Forsyth, D. Performance comparisons between PIN and APD photodetectors for use in optical communication systems. Opt. Int. J. Light Electron Opt. 2013, 124, 1493-1498.

17. International Telecommunication Union. Optical fibres, cables and systems. In ITU-T Manual 2009, 2010.

18. International Telecommunication Union. Characteristics of adaptive chromatic dispersion compensators; Recommendation ITU-T G.667, 2006.

19. International Telecommunication Union. Characteristics of polarization mode dispersion compensators and of receivers that compensate for polarization mode dispersion; Recommendation ITU-T G.666, 2011.

20. Nielsen, M.D.; Jacobsen, C.; Mortensen, N.A.; Folkenberg, J.R.; Simonsen, H.R. Low-loss photonic crystal fibers for transmission systems and their dispersion properties. Opt. Express 2004, 12, 1372-1376.

21. Chowdhury, P.; Tornatore, M.; Sarkar, S.; Mukherjee, B. Building a Green Wireless-Optical Broadband Access Network (WOBAN). J. Lightwave Technol. 2010, 28, 2219-2229. 
22. Ennser, K.; Devlin, B.; Mangeni, S. Towards Greener Optical Access Networks. In Proceedings of the 12th International Conference on Transparent Optical Networks (ICTON), Munich, Germany, 27 June-1 July 2010.

23. European Commission. Communication Europe 2020: A strategy for smart, sustainable and inclusive growth. In the Communication from the Commission Europe 2020, Brussels, Belgium, 3 March 2010.

24. Ecobilian, S.A. Developing a Generic Approach for FTTH Solutions Using LCA Methodology; FTTH Council Europe: Paris, France, February 2007.

25. Jacobs, S. Security management of next generation telecommunication networks and services; Wiley-IEEE Press: Hoboken, NJ, USA, 2013.

26. Gaede, S.; Schaeffer, C.G. Overview of Optical Monitoring in Next Generation Optical Access Networks. In Proceedings of the Photonic Networks ITG Symposium, Leipzig, Germany, 2-3 May 2011.

27. Park, J.; Baik, J.; Lee, C. Fault-detection technique in a WDM-PON. Opt. Express 2007, 15, 1461-1466.

28. Mendes Lima, G.F.; Lamounier, E.A.; Cardoso, A.; Santos Peretta, I.; Barcelos, S.; Sadaiti Muramoto, W.; Rigon, E. A TEO-Based Algorithm to Detect Events Over OTDR Measurements in FTTH PON Networks. Lat. Am. IEEE Trans. 2013, 11, 886-891.

29. Rad, M.M.; Fouli, K.; Fathallah, H.A.; Rusch, L.A.; Maier, M. Passive Optical Network Monitoring: Challenges and Requirements. IEEE Commun. Mag. 2011, 42, s45-s52.

30. Lee, K.; Kang, S.; Lim, D.S.; Lee, H.K.; Sorin, W.V. Fiber Link Loss Monitoring Scheme in Bidirectional WDM Transmission Using ASE-Injected FP-LD. IEEE Photonics Technol. Lett. 2006, 18, 523-525.

31. Hülsermann, R.; Breuer, D.; Lange, C. Impact of network reliability on network costs in next generation access networks. In Proceedings of the 12th International Conference on Transparent Optical Networks (ICTON), Munich, Germany, 27 June-1 July 2010.

32. Mitsui, T.; Sakamoto, T.; Hara, K.; Yoshimoto, N. Flexible and scalable PON protection architecture using N:M redundancy toward Next Generation Access Network. In Proceedings of the 17th Asia-Pacific Conference on Communications (APCC), Sabah, Malaysian, 2-5 October 2011.

33. Huang, A.; Liu, S.; Xie, L.; Chen, Z.; Mukherjee, B. Self-healing optical access networks (SHOAN) operated by optical switching technologies. IEEE Trans. Netw. Serv. Manag. 2011, 8, 234-244.

34. P'ng, W.T.; Abdullah, M.K.; Khatun, S.; Ahmad-Anas, S.B.; Shaari, S. Protection networking of Ethernet PON FTTH access network. In Proceedings of the 7th International Conference on Laser and Fiber-Optical Networks Modeling, Yalta, Crimean, 15-17 September 2005.

35. De Bortoli, M.; Mercinelli, R.; Solina, P.; Tofanelli, A. Tecnologie ottiche per 1'accesso: Le soluzioni Passive Optical Network. Notiziario Tecnico-Telecom Italia 2004, 1, 104-119.

36. Grobe, K.; Elbers, J. PON in Adolescence: From TDMA to WDM-PON. IEEE Commun. Mag. 2008, 46, 26-34.

37. International Telecommunication Union. Spectral grids for WDM applications: CWDM wavelength grid; Recommendation ITU-T G.694.2, 2003. 
38. International Telecommunication Union. Spectral grids for WDM applications: DWDM frequency grid; Recommendation ITU-T G.694.1, 2002.

39. Segarra, J.; Sales, V.; Prat, J. Agile Reconfigurable and Traffic Adapted All-Optical Access-Metro Networks. In Proceeding of the 11th International Conference on Transparent Optical Networks ICTON, Azores, Portugal, 28 June-2 July 2009.

40. Wu, Y.; Ye, T.; Zhang, L.; Hu, X.; Li, X.; Su, Y. A cost-effective WDM-PON architecture simultaneously supporting wired, wireless and optical VPN services. Opt. Commun. 2011, 284, 1139-1145.

41. Kitayama, K.; Wang, X.; Wada, N. OCDMA over WDM PON-Solution Path to Gigabit-Symmetric FTTH. J. Lightwave Technol. 2006, 24, 1654-1662.

42. Abda, T.H.; Aljunida, S.A.; Fadhila, H.A.; Ahmad, R.; Arief, A.R. Design and Evaluation Fiber-to-the-Home Network Based on DCS Code. In Proceedings of the IEEE 3rd International Conference on Photonics (ICP), Penang, Malaysia, 1-3 October 2012.

43. Tamai, H.; Sarashina, M.; Iwamura, H.; Kashima, M.; Gupta, G.C.; Ushikubo, T.; Kamijoh, T.; Chanclou, P.; Genay, N.; Landousies, B.; et al. First Demonstration of Coexistence of Standard Gigabit TDM-PON and Code Division Multiplexed PON Architectures toward Next Generation Access Network. J. Lightwave Technol. 2009, 27, 292-298.

44. Hernández, M.; Arcia, A.; Alvizu, R.; Huerta, M.; Bolivar, S. A Review of XDMA-WDM-PON for Next Generation Optical Access Networks. In Proceedings of the Global Information Infrastructure and Networking Symposium (GIIS), Choroni, Venezuela, 17-19 December 2012.

45. Ossieur, P.; Antony, C.; Clarke, A.M.; Naughton, A.; Krimmel, H.G.; Chang, Y.; Ford, C.; Borghesani, A.; Moodie, D.; Poustie, A.; et al. A 135-km 8192-Split Carrier Distributed DWDM-TDMA PON with $2 \times 32 \times 10 \mathrm{~Gb} / \mathrm{s}$ Capacity. J. Lightwave Technol. 2011, 29, 463-474.

46. Cincotti, G.; Kataoka, N.; Wada, N.; Kitayama, K. Future passive optical networks: Can CDM beat WDM? In Proceedings of the Future Network \& Mobile Summit Conference, Florence, Italy, 16-18 June 2010.

47. Cvijetic, N.; Cvijetic, M.; Huang, M.; Ip, E.; Huang, Y.; Wang, T. Terabit Optical Access Networks Based on WDM-OFDMA-PON. J. Lightwave Technol. 2012, 30, 493-503.

48. Hu, X.; Zhang, L.; Cao, P.; Wang, K.; Su, Y. Energy-efficient WDM-OFDM-PON employing shared OFDM modulation modules in optical line terminal. Opt. Express 2012, 20, 8072-8077.

49. Chung, Y.C. High-Speed Coherent WDM PON for Next-Generation Access Network. In Proceedings of the 15th International Conference on Transparent Optical Networks (ICTON), Cartagena, Spain, 23-27 June 2013.

50. Chiuchiarelli, A.; Proietti, R.; Presi, M.; Choudhury, P.; Contestabile, G.; Ciaramella, E. Symmetric $10 \mathrm{~Gb} / \mathrm{s}$ WDM-PON based on a Cross Wavelength-Reusing Scheme to Avoid Rayleigh Backscattering and Maximize Band Usage. In Proceedings of the LEOS Annual Meeting Conference, Belek-Antalya, Turky, 4-8 October 2009.

51. Cho, K.Y.; Hong, U.H.; Jung, S.P.; Takushima, Y.; Agata, A.; Sano, T.; Horiuchi, Y.; Suzuki, M.; Chung, Y.C. Long-reach 10-Gb/s RSOA-based WDM PON employing QPSK signal and coherent receive. Opt. Express 2012, 20, 15353-15358. 
52. Aamer, M.; Sotiropoulos, N.; Brimont, A.; Fedeli, J.; Marris-Morini, D.; Cassan, E.; Vivien, L.; Ribaud, K.; Grosse, P.; Hartmann, J.M.; et al. A Silicon Differential Receiver with Zero-Biased Balanced Detection for Access Networks. J. Lightwave Technol. 2013, 25, 1207-1210.

53. Liu, B.; Xin, X.; Zhang, L.; Yu, J.; Zhang, Q.; Yu, V. A WDM-OFDM-PON architecture with centralized lightwave and PolSK-modulated multicast overlay. Opt. Express 2010, 18, 2137-2143.

54. Malti Sharma, M.; Sheetal, A. Comparison of CSRZ, DRZ and MDRZ Modulation Formats for High Bit Rate WDM-PON System using AWG. Int. J. Emerg. Technol. Adv. Eng. 2012, 2, 83-87.

55. Liu, Z.; Xu, J.; Qiu, Y.; Chan, C. An 80-km-Reach Centralized-light-source WDM PON utilizing Inverse-RZ Duobinary Downstream Signals. In Proceedings of the 36th European Conference and Exhibition on Optical Communication (ECOC), Torino, Italy, 19-23 September 2010.

56. Guo, Q.; Tran, A.V. Mitigation of Rayleigh noise and dispersion in REAM-based WDM-PON using spectrum shaping codes. Opt. Express 2012, 20, B452-B461.

57. Maalouf, A.; Bastianelli, C.; Mahé, F.; Belmiloudi, A.; Gadonna, M.; Bosc, D. Improved integrated resonators in polymer technology for tunable filter. Proc. SPIE 2012, doi:10.1117/12.906183.

58. Kim, H.; Choi, B.; Kim, K.; Kim, D.; Kwon, O.; Oh, D. Improvement of modulation bandwidth in multisection RSOA for colorless WDM-PON. Opt. Express 2009, 17, 16372-16378.

59. Borghesani, A. Reflective Based Active Semiconductor Components for Next Generation Optical Access Networks. In Proceedings of the 36th European Conference and Exhibition on Optical Communication (ECOC), Torino, Italy, 19-23 September 2010.

60. Presi, M.; Proietti, R.; Prince, K.; Contestabile, G.; Ciaramella, E. A $80 \mathrm{~km}$ reach fully passive WDM-PON based on reflective ONUs. Opt. Express 2008, 16, 19043-19048.

61. Cavaliere, F.; Ponzini, F.; Presi, M.; Ciaramella, E. Migration towards High Speed Optical Access Enabled by WDM Techniques. In Proceedings of the Communications and Photonics Conference and Exhibition (ACP), Shanghai, China, 2-6 November 2009.

(C) 2014 by the authors; licensee MDPI, Basel, Switzerland. This article is an open access article distributed under the terms and conditions of the Creative Commons Attribution license (http://creativecommons.org/licenses/by/4.0/). 